\title{
Designing trials of Universal Basic Income for health impact: identifying interdisciplinary questions to address
}

\author{
Matthew Thomas Johnson, ${ }^{1}$ Elliott Aidan Johnson, ${ }^{2}$ Daniel Nettle ${ }^{3}$ and Kate Pickett ${ }^{4}$
}

\begin{abstract}
A large body of evidence indicates the importance of upstream determinants to health. Universal Basic Income (UBI) has been suggested as an upstream intervention capable of promoting health by affecting material, biopsychosocial and behavioural determinants. Calls are emerging across the political spectrum to introduce an emergency UBI to address socio-economic insecurity. However, although existing studies indicate effects on health through cash transfers, UBI schemes have not previously been designed specifically to promote health. In this article, we scope the existing literature to set out a set of interdisciplinary research challenges to address in designing a trial of the effectiveness of UBI as a population health measure. We present a theoretical model of impact that identifies three pathways to health impact, before identifying open questions related to regularity, size of payment, needs-based supplements, personality and behaviour, conditionality, and duration. These set, for the first time, a set of research activities required in order to maximise health impact in UBI programmes.
\end{abstract}

Keywords: Public health; Universal Basic Income; public policy; socio-economic status

The UK Government introduced a Green Paper on health advancing a 'prevention agenda' (Department of Health and Social Care 2019). With concern about the NHS being understood as the 'National Hospital Service' (see Department of Health and Social Care and Hancock 2018), there is an emerging commitment to promote action conducive to avoidance of illhealth. In that context, a large body of evidence indicates the relationship between socioeconomic status and income and health outcomes, as has been evident in COVID-19 mortality rates. A recent issue of The Lancet Public Health (2020) explores that relationship in modern Britain and examines the effect of 'upstream interventions' on health. We have suggested that Universal Basic Income - an unconditional, regular cash transfer to all adult citizens - could serve as one such intervention by affecting material, biopsychosocial and behavioural pathways to health (Johnson, Johnson and Webber 2020). In part because of this research, the UK Labour Party committed to trialling UBI in such cities as Liverpool and Sheffield in its 2019 Manifesto (see Standing 2019, 17-19; Labour Party 2019, 60). Demonstrating cross-party support for the policy, Hull City Council has sought permission to conduct a trial of UBI in the wake of the Conservative Party's success in the 2019 General Election (Halliday 2019), while the Scottish National Party has called for its emergency introduction during the COVID-19 pandemic (Crerar 2020).

The fact that policy makers are concerned with trialling the policy indicates both the expected controversy attached to granting citizens 'free money' and belief that evidence-based-

\footnotetext{
${ }^{1}$ Senior Lecturer in Politics, Lancaster University. Politics, Philosophy and Religion, County South, Lancaster University, Lancaster, United Kingdom, LA1 4YL. ORCID ID: 0000-0002-9987-7050. m.johnson@lancs.ac.uk

${ }^{2}$ Disability Research Consultant. ORCID ID: 0000-0002-0937-6894. ejohnsonresearch@ gmail.com

${ }^{3}$ Professor of Behavioural Science, Newcastle University. ORCID ID: 0000-0001-9089-2599. daniel.nettle@newcastle.ac.uk

${ }^{4}$ Professor of Epidemiology, University of York. ORCID ID: 0000-0002-8066-8507. kate.pickett@york.ac.uk
} 
policy retains the capacity to transform public opinion (see Roberts and King 1991). These assumptions persist despite concern about the ineffectiveness of quantitative data in securing public support (see Macintyre 2012) and the possibility of confirmation bias, in which evidence is interpreted through the lens of existing beliefs - the notion of 'policy-based evidence' (see Saltelli and Giampetro 2017). While empirical examination of UBI is catching up with the extensive body of theoretical work (see Ruckert, Huynh and Labonté 2018), studies conducted on cash transfers are of such varying quality, scale and focus that few substantive conclusions can be drawn on the policy's potential effect on health. In this article, we scope the existing literature to set out a set of interdisciplinary research challenges to address in creating an effective UBI trial for health promotion. We set out the parameters of existing trials and map out three pathways to health impact before identifying challenges related to regularity, size of payment, needs-based supplements, personality and behaviour, conditionality, and duration. We do not present this work as comprehensive (or the reviews as systematic), but as the first attempt to codify the questions that need to be answered in advance of and during trials.

\section{Data from existing cash transfers}

UBI is a system of universal cash transfers to (adult) citizens. It ensures a minimum income, but, unlike the UK's Universal Credit (Government Digital Service 2020), is not allocated on the basis of need or means. It is often associated with left-wing political parties, but has been supported by thinkers across the political spectrum as a means of promoting rights (Pettit 2007), efficiency (Gordon 2014), growth (Sheahan 2003) and supporting flexibility in the labour market (Harrop \& Tait, 16). Because UBI has previously been seen as an economic instrument, the notion of deploying UBI specifically for reasons of public health, and grounding those reasons in the medical literature, marks a key development within the field (Johnson, Johnson and Webber 2020).

However, before we can consider that case, it is essential to clarify that there have been few examples of cash transfer programmes in general and those presented as comparable to UBI differ significantly in ways that may restrict the generalisability of findings. Perhaps the most commonly cited examples of trials are those that relate to Negative Income Tax (NIT) provision. NIT schemes ensure that citizens' incomes reach a basic threshold by providing payment where income from other sources fails to meet the threshold, with payment gradually tapering and being replaced by taxation as incomes from other sources increase. Gibson, Craig and Hearty $(2018,28)$ identified five NIT trials in North America: the New Jersey Graduated Work Incentive Experiment (Kershaw and Fair 1976), the Rural Income Maintenance Experiment (RIME) (Bawden and Harrar 1978), the Gary Income Maintenance Experiment (Kehrer and Wohlin 1979), the Seattle/Denver Income Maintenance Experiment (SIME/DIME) (Widerquist 2005) and the Manitoba Basic Annual Income Experiment (Mincome) (Forget 2011). These targeted interventions were much closer to Universal Credit in the UK and lacked both the universality and unconditionality of UBI. The same is true of the 2017-2018 Finnish trial, which constituted an unconditional minimum income guarantee for benefit claimants (see Kangas, et al. 2019).

Whereas these schemes differ in terms of their being conditional on low income, other systems differ in terms of their being conditional on an individual's membership of an ethnic group, rather than citizenship of a country. These include the US case of Tribal Casino Cash Transfers (such as the Great Smoky Mountains Study), in which Indigenous Americans receive twice annual taxable cash payments (Akee, et al. 2013). Beyond this, while proponents of UBI in liberal democracies generally support weekly or monthly transfers to mimic salaries, the Tribal transfers and the Alaska Permanent Dividend Fund involve annual or biannual transfers (see Widerquist and Sheahen 2012). 
Moreover, even programmes designed experimentally to examine impact of cash transfers on indicators of health and wellbeing differ radically. For example, Haushofer and Shapiro's (2016) trial of unconditional cash transfers to low-income household units in Kenya not only focused on households instead of individuals, it also involved trialling payments to the husband and the wife, varying the size of the payment and using lump-sum and monthly payment schedules (Haushofer and Shapiro 2018). In the Madhya Pradesh Unconditional Cash Transfer Pilot (MPUCT), payments of varying sizes to adults and children within villages were made via bank and physical 'cash-in-hand' transfers over 12 months. However, this was not permanent and represented an extremely low proportion of the cost of living for the very poorest in Indian society (see SEWA Bharat 2014).

As a universal benefit, UBI cannot be properly evaluated without evidence of its impact on all individuals, including those from middle and higher socioeconomic backgrounds. Moreover, some of the health effects may be emergent on the policy's being applied at population scale, rather than restricted or experimental subsets. As such, contrary to assertion in other accounts (see Haagh and Rohregger 2019), no trial of an unconditional, universal payment across a population encompassing all individuals irrespective of socio-economic status has occurred, meaning that evidence of impact has to be carefully contextualised.

\section{Evidence of impact on health}

Given the disparate nature of studies, findings presented as evidence of the impact of the policy have to be understood as necessarily limited and context specific. However, trials of programmes that resemble elements of UBI have noted an effect on health (Haagh and Rohregger 2019). Kangas, et al. $(2019,24)$ found that respondents in the Finnish trial reported reduced stress related to economic circumstances. In May, 2020, the Finnish Ministry of Social Affairs and Health reported that analyses of the full trial showed that those who received the UBI 'described their wellbeing more positively than respondents in the control group. They were more satisfied with their lives and experienced less mental strain, depression, sadness and loneliness' (Basic Income Today 2020). The US case of Gary Indiana, in which low income families received a minimum income guarantee, demonstrated a positive impact on birth weight (Kehrer and Wohlin 1979). Similarly, Chung et al.'s (2016) study of the Alaska Permanent Fund Dividend - which varies each year and was distributed to every individual residing there for more than six months - found that birthweight increased by $17.7 \mathrm{~g}$ per $\$ 1,000$ received by the household compared with babies born in states with the same observable birthweight pattern in the pre-treatment period. The likelihood of low birthweight was also reduced by $14 \%$ ( 0.7 percentage points). The MPUCT pilot was associated with a $46 \%$ reduction in illness and injury not requiring inpatient hospital treatment, but no impact on more serious ill-health, perhaps because of the limited period of intervention (Beck, et al. 2015). Forget's (2011) study of Mincome established a series of impacts, such as decreased hospital admissions and improved adult mental health, the latter of which was also found in RIME (Hannan 1978). Using Great Smoky Mountains Study data, Costello, et al. (2010) found reduced rates of psychiatric and substance abuse disorders among children whose family income was supplemented as a result of the Tribal payments compared with non-tribal children. This effect persisted into adulthood.

Not all the impacts are health-promoting. Evans and Moore (2011) demonstrate a 13\% increase in deaths among urban Alaskans in the week following annual payment of the Alaska dividend. Bruckner, et al. (2011) found that the risk of accidental death more than doubled in the month after the biannual Eastern Cherokee payment. While there is prima facie reason to suppose that the severity of impact associated with sudden (bingeing) increase in activity in response to the lump sum (including through alcohol and narcotic consumption) would not be 
as marked with weekly or monthly payments, this can only be verified through examination of the effect of such payments at population level.

\section{Pathways to health impact}

We suggest that are three main qualitatively distinct, but potentially mutually reinforcing, prospective biopsychosocial pathways to impact on health (see Johnson, Johnson and Weber 2020). Each relates to the effect of the intervention on the social determinants of health. Our model of impact (see fig. 1) builds upon and expands the findings of The Black Report (Working Group on Inequalities in Health 1980), but assesses UBI as a universal upstream intervention as opposed to the targeted interventions proposed in the Report's recommendations. 
UBI model of impact

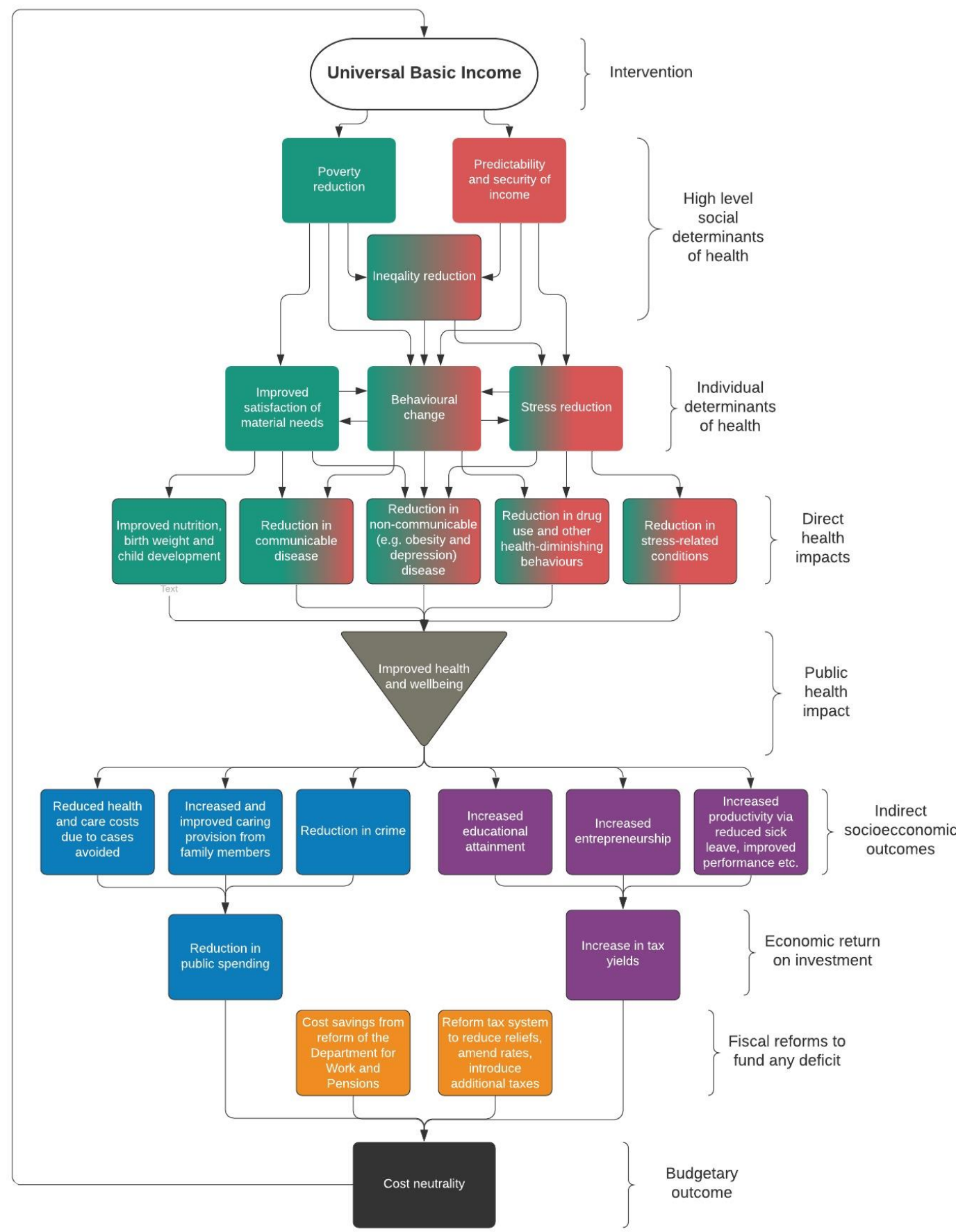

Figure 1. UBI model of impact

The first pathway is impact on resource scarcity. Absolute poverty imposes limits on the quality and quantity of resources to which individuals have access in satisfying their needs. Where UBI increases resources and reduces absolute poverty, there is potential for improvement in material capacity for promotion of health (see Johnson, Degerman and Geyer 2019). This pathway is supported by reported increases in food sufficiency in several programmes (see Gary, RIME, MPUCT and Casino). 
The second pathway is impact on chronic stress (see Johnson and Johnson 2018). Stress is an evolutionary adaptation that effects a cascade of biological changes that prime the body to respond first psychologically and then biologically to threatening stimuli (Schneiderman, Ironson and Siegel, 2005, 612). The medical literature indicates that long-term exposure to stress is linked to a number of health conditions (see Cohen et al., 2012). Chronic psychological stress is 'associated with a greater risk of depression, cardiovascular disease (CVD), diabetes, autoimmune diseases, upper respiratory infections (URIs), and poorer wound healing' (Cohen et al., 2012, 5995). Stimuli for stress all relate to unpredictability (van der Kolk 2014). When individuals feel subject to processes that can lead to destitution, they are left in a state of perpetual preparedness for threat (see Howard, 2005, 621-622). This includes the judgement of others - social evaluative threat (see Dickerson \& Kemeny 2004) where that judgement serves as a cue for exclusion or domination by removing social sources of predictability (group bonds, shared resources, absence of inter-subjective threat). This is a relative, rather than absolute, source of ill-health. Where UBI can provide a bulwark against destitution, it can serve as a stress-reducing means of ameliorating 'health inequalities and the structural conditions that put people "at risk of risks" (Thoits, 2010, S47). As Kangas, et al. $(2019,25)$ put it, "The predictability of the basic income is thought to reduce the level of stress due to less bureaucracy and more certain flow of income'.

The third pathway relates to behaviour. Individuals facing scarcity or unpredictability in their lives may invest less in behaviours that positively promote their long-term health and well-being (Pepper and Nettle 2017). Explanations for this foreshortening of perspective differ, from scarcity causing a restriction on the available cognitive resources required to make good long-term decisions (Mullainathan and Shafir 2014), to a more immediate focus being a rational response to situations where there are immediately pressing challenges or the longterm future is uncertain (Nettle 2010; Mell, Baumard and André 2019). Perception of inequality can also induce violent and dangerous behaviours; individuals in situations of disadvantage who perceive little prospect of 'catching up' with the rest of society through legitimate means may be more likely to opt for these (Daly 2016). One advantage of UBI schemes is that they mark out all members of society as equal in an important and visible sense: all get an equal share, and do not have to go through assessments that some find demeaning (See Johnson, Degerman and Geyer 2019), in which they are powerless, in order to get it. Thus, their effect on perceived inequality may be greater than their actual redistributive effect.

The conditionality of current welfare systems can exacerbate behavioural effects on health: individuals may choose behaviours that diminish their health in order to qualify for conditional welfare support (see Johnson and Spring 2018; Activity Alliance and IFF Research 2020); or may avoid addressing underlying conditions for fear of losing pay (see Johnson, Degerman and Geyer 2019). By increasing anticipated long-term survival and by removing behavioural disincentives to health, UBI may foster health-promoting decisions. This may be indicated by a decrease in health-reducing behaviour among recipients of Tribal Cash Transfers (see Costello et al. 2010).

While these theoretical pathways to health impact require verification through empirical study in trials, their grounding in broader literatures means that they must necessarily serve to inform design of those trials.

\section{Designing trials for health impact}

Because UBI has been advanced most keenly by economists, trials have often been designed specifically with effects on employment, consumption and growth in mind (see Kangas, et al. 2019). However, designing trials to achieve health and wellbeing impact as one of several qualitatively distinct, but related, outcomes, requires a different set of considerations. Given the existing evidence of differential impact of transfer programmes depending on regularity, 
size of payment and duration and given the theoretical pathways outlined above, several key considerations require examination.

\section{Regularity}

The clearest evidence established from studies of transfers is that, whatever the size of transfer, the transfer's being regular and predictable reduces negative impacts associated with lumpsum payments (see Moore 2011; Bruckner, et al. 2011). Regular transfers not only avoid promotion of bingeing, they also increase predictability. This reduces actual or perceived precariousness of income and enables individuals to adopt health-promoting behaviour (see Johnson, Degerman and Geyer 2019). However, more work needs to be conducted by health economists to consider the relative merits of weekly and monthly transfers - the two most common patterns of payment in the UK.

\section{Size of payment}

The most significant concern is size of payment. The Finnish trial found that a $€ 560$ payment per month had a significant effect on self-rated stress and other psychological aspects of wellbeing (Kangas et al. 2019, 25) although the size of transfer was determined solely on the basis of replacing the usual unemployment benefit at the same rate. Given differing economic and cultural expectations in different countries, and even regions, the starting point for policy work grounded in concern for each of the pathways must be to establish the cost of living.

One possible approach deploys relative poverty as a measure of a minimum standard, which in the UK is considered to be less than $60 \%$ of the median salary (McGuinness, Booth and Francis-Devine 2019, 43). However, given that there is cultural variance in what constitutes an intolerable existence (see Johnson and Johnson 2019, 262), the psychological component of the stress-based pathway to health promotion is relative. As such, there may be good reason to focus on negotiated consensus as a means of ascertaining the size of transfer. The Joseph Rowntree Foundation's Minimum Income Standard (MIS) seeks to determine what households need for 'a decent living standard, considered the minimum by the general public' (Hirsch 2019,4). This means more than survival alone, and enough for healthy living (see Morris, Donkin \& Wonderling, et al. 2000), which would be consistent with the capabilities approach (Nussbaum 1999, 40). MIS is determined by 'negotiated consensus' within groups composed of individuals representing the household type under discussion (see Davis et al. 2015). The Living Wage Foundation's (2020) calculations provide a starting point as they are informed by MIS, but not grounded in health promotion. Determining an impactful sum depends upon collaboration between epidemiologists and health economists, among others.

\section{Needs-based supplements}

The MIS does not cover additional needs that some individuals, such as disabled people, might possess (Hirsch 2019, 4). The capabilities approach (Sen 1980, 215-216) acknowledges individual differences in need and means that a blanket policy such as UBI runs the risk of diminishing the health of those with additional needs if it is not sufficient to support those needs specifically. Research by Scope (John, Thomas and Touchet 2019) suggests that disabled adults face additional costs of $£ 583$ per month to have the same standard of living as nondisabled people.

The main UK disability benefit is Personal Independence Payment (PIP), which started to replace Disability Living Allowance in 2013. This is allocated on the basis of assessed need - the impact of impairments and health conditions -, not means. The purpose of PIP is to enable disabled people to procure support and services through market mechanisms. Further support is provided through the weekly Carers' Allowance (CA) to individuals who care nonprofessionally for a disabled person for at least 35 hours per week. 
One of the key justifications for UBI is its elimination of bureaucratic complexity and assessment. Apart from removing arbitrary discrimination in assessment see Pybus, et al. 2019), Johnson, Degerman and Geyer (2019) suggest that it may also remove perverse incentives in the needs-based welfare system for unhealthy behaviour. Many additional needs could potentially be met through bolstered public services - such as through the Labour Party's (2019) proposal for a Social Care Service - and provision of transport. However, given the apparent importance of autonomy to wellbeing (see Nussbaum 1999), there may be concern that reduction in individuals' autonomy over procuring services may serve to diminish health. This has not adequately been examined in the health literature, although the disability rights movement has strongly advocated systems that promote autonomy in decision-making (Disability Rights UK 2014).

It may be that a trial should focus solely on replacement of means-tested, and leave in place needs-tested, benefits. Alternatively, an experimental model that assesses impact of including a needs-tested element could be developed.

\section{Personality and behaviour}

A recurring criticism of UBI is that it constitutes an incentive for behaviour conducive to illhealth and idleness. Anderson (2000), for example, argues that UBI promotes freedom without responsibility and undermines social obligation to work. Given that inactivity can contribute to ill-health, there are reasons to examine this seriously. Evidence from a nationwide Iranian system of transfers (Salehi-Isfahani and Mostafavi-Dehzooei 2018) and an analysis of 16 Basic Income Guarantee trials (Gilbert et al. 2018) indicates that transfers result in no meaningful reductions in employment-related activity, while, the final report for the Finnish trial found thats the employment rate for UBI recipients improved slightly more than for the control group (Basic Income Today 2020).. Moreover, to the extent there is any evidence relating to longterm effects of unconditional cash transfers on behaviour and personality, it tends to document positive rather than negative effects overall. Akee, Copeland, Costello and Simeonova (2018, 777) found that an 'increase in unconditional household income improves child personality traits, emotional well-being, and behavioral health'. Mehra, Stopnitzky and Alloush's (2018) study of poor households in Uganda found that a poverty graduation programme increased scores on traits that represent socialization and stability, while drought had the opposite effect. This may be because reducing uncertainty and precariousness allow a longer-term outlook, as discussed under 'Pathways to health impact'.

\section{Conditionality}

The proliferation of claims, such as Anderson's, on the effect of UBI on behaviour indicates the possibility of unintended consequences and the importance of securing and retraining public and policymaker support. A trial must therefore consider what conditions can plausibly be attached to UBI to uphold civic goods.

Atkinson (1996, 68-9) suggested a 'participation income' dependent upon participation in the labour market, including through entrepreneurship, education, training, voluntary work or caring. However, this simply replaces the 'negative' testing UBI is intended to eliminate, with 'positive assessment' of participation which is perhaps even more impractical administratively. Very simple conditions, such as electoral participation, could potentially avoid these issues. What may be required, however, is disqualification from a default of being awarded basic income. Van Parijs $(2004,11)$ argues that prisoners, along with individuals living in state care homes or hospital facilities, would be disqualified since the cost to the community of care exceeds the value of the income. He proposes that the payment would be reinstated if and when this situation ends. Again, given the known and unknown elements of 
need and behaviour, designing for impact on health requires significant further work between social psychologists and legal scholars, among others.

\section{Duration}

For clear financial reasons, the interventions studied are generally short-term, even if the data on health cover a much longer period. The 2018 Finnish trial was not extended beyond two years, despite calls from the nation's social security agency to do so (Henley 2018). Reporting of this decision focused on the schemes' 'failure', in preliminary analyses, to increase employment, despite improved wellbeing for participants (Henley and agencies 2019; Pohjanpalo 2019). This perceived failure resulted from the centre-right Government's narrow policy objectives, which focused solely on reducing unemployment (Valero 2019) and ultimately the UBI recipients were shown to have increased employment more than controls. The pathways to health noted above require that individuals perceive their circumstances to be predictable and secure in order for changes in behaviour to be felt and health outcomes measured. Practically, Government funding can likely only be committed to cover a period equal to an electoral cycle minus the time taken to establish a funding stream and project. In the UK Parliamentary system, this leaves perhaps a period of approximately three years.

It is clear is that the duration of a pilot needs to be sufficiently long to replicate a 'feeling' of enduring income security. The pathways to health impact noted above are unlikely to be demonstrable if a cliff-edge return to insecurity is looming within the data-collection period. There are several options available that could be explored to achieve this, including ensuring match funding from national and local government, which could be used consecutively to overlap separate budget periods with short-term and medium-term goals for each partner. Again, establishing this requires collaboration between psychologists, epidemiologists and policy makers. The possibility that political considerations preclude a longer trial means that there needs to be serious methodological examination of means of evaluating health impact via proxy measures, such as self-rated health and stress, as well as deaths and health service utilization and biomarkers, such as inflammation. Without comprehensive measurement, a short trial may underestimate long-term effects, many of which would emerge through prevention from income shocks for a prolonged period of individuals' lives. Moreover, given that the aetiological period of behaviours, such as smoking, extends into decades (see Doll, et al. 2004), and given that one prospective impact of UBI is to affect behaviour, it is likely that modelling will be an essential feature of evidence gathering (Johnson, Johnson and Webber 2020).

\section{Conclusion}

This article scopes a series of tasks to be completed in designing UBI specifically for health impact, and assessing its impact as an upstream health impact. That substantive interdisciplinary collaboration on the areas above has not taken place prior to other trials highlights the extent to which the potential value of UBI to health has been overlooked. We leave aside the economic concerns of cost and means of measuring health impact for examination elsewhere. We note, however, that given the magnitude of healthcare expenditures in all developed countries, any substantial improvement in population health brought about by the introduction of UBI would lead to savings that make the policy much more economically attractive than appears from consideration of the economic case alone (see Johnson and Johnson 2019). At a time in which governments are devoting hundreds of billions of pounds to dealing with the Covid-19 pandemic, the scope of the financial costs that are thinkable has greatly changed. In that light, one consideration that we cannot address here is that of scale. The smaller the trial, the smaller the impact of individual-level effects on the economy, such as on inflation, housing costs and wages. If governments are serious about trials as a means of 
providing evidence for policy, any such UBI trial needs to be large - perhaps at whole city level - in order for side-effects and unintended consequences of payments to individuals to become clear. It may be that benefits are outweighed by costs, but only a trial can enable us to know definitively what those benefits and costs are and to make a determination on how they may best be balanced.

\section{References}

Activity Alliance and IFF Research (2020) Annual Disability and Activity Survey 2019/20, Loughborough: Activity Alliance.

Akee, R., Copeland, W., Costello, E. J. and Simeonova, E. (2018) 'How Does Household Income Affect Child Personality Traits and Behaviors?', American Economic Review, 108(3): 775-827.

Akee, R., Simeonova, E., Copeland, W., Angold, A. and Costello, E. J. (2013) 'Young Adult Obesity and Household Income', American Economic Journal, 5(2): 1-28.

Anderson, E. (2000) 'Optional Freedoms', Boston Review (Online), 1 October, <http://bostonreview.net/forum/basic-income-all/elizabeth-anderson-optionalfreedoms $>$ [Accessed 14 February 2020].

Atkinson, A. B. (1996) 'The Case for a Participation Income'. The Political Quarterly, 67: 6770.

Basic Income Today (2020) 'The Final Results of Finland's Basic Income Experiment', Basic Income Today, 7 May, < https://basicincometoday.com/the-final-results-of-finlandsbasic-income-experiment/> [Accessed 29 May 2020].

Bawden, D. L. and W. S. Harrar (1978) 'Design and Operation', in J. Palmer and J. Pechman (eds), Welfare In Rural Areas: The North Carolina-Iowa Income Maintenance Experiment, Washington DC, Brookings Institution, pp. 23-54.

Beck, S., Pulkki-Brannstrom, A. M. and San Sebastian, M. (2015) 'Basic income: healthy outcome?', Journal of Development Effectiveness, 7(1): 111-126.

Bruckner, T. A., Brown, R. A. and Margerison-Zilko, C. (2011) 'Positive income shocks and accidental deaths among Cherokee Indians', International Journal of Epidemiology, 40(4): 1083-1090.

Chung, W., Ha, H. and Kim, B. (2016) 'Money transfer and birth weight', Economic Inquiry, 54(1): 576-590.

Cohen, S., Janicki-Deverts, D., Doyle, W. J., Miller, G. E., Frank, E., Rabin, B. S. and Turner, R. B. (2012) 'Chronic stress, glucocorticoid receptor resistance, inflammation, and disease risk', Proceedings of the National Academy of Sciences, 109(16), 5995-5999.

Costello, E. J., Erkanli, A., Copeland, W. and Angold, A. (2010) 'Association of family income supplements in adolescence with development of psychiatric and substance use disorders in adulthood among an American Indian population experiment', Journal of the American Medical Association, 303(19): 1954-1960.

Crerar, P. (2020) 'Coronavirus', The Mirror, 18 March, $<$ https://www.mirror.co.uk/news/politics/breaking-coronavirus-private-rentersprotected-21713009> [Accessed 19 March 2020].

Daly, M. (2016) Killing the Competition, Abingdon: Transaction.

Davis, A., Hirsch, D., Padley, M. and Marshall, L. (2015) How much is enough?, Loughborough: Loughborough University.

Department of Health and Social Care (2018) Prevention is better than cure, London: GOV.UK, <https://assets.publishing.service.gov.uk/government/uploads/system/uploads/attachm ent_data/file/753688/Prevention_is_better_than_cure_5-11.pdf > [Accessed 10 January 2019]. 
Department of Health and Social Care and Hancock, M. (2018) 'Prevention is better than cure', GOV.UK

(Online), 5

November, $<$ https://www.gov.uk/government/speeches/prevention-is-better-than-cure-matthancocks-speech-to-ianphi> [Accessed 10 January 2019].

Department for Work and Pensions (2019) Benefit expenditure and caseload tables 2019, London: Department for Work and Pensions, $<$ https://www.gov.uk/government/publications/benefit-expenditure-and-caseloadtables-2019> [Accessed 19 February 2020].

Dickerson, S. \& Kemeny, M. (2004) Acute Stressors and Cortisol Responses. Psychological bulletin, 130. 355-91.

Disability Rights UK (2014) Independent Living, $<$ https://www.disabilityrightsuk.org/independent-living-0> [Accessed 25 February 2020].

Doll, R., Peto, R., Boreham, J., \& Sutherland, I. (2004) Mortality in relation to smoking: 50 years' observations on male British doctors. BMJ, 328(7455): 1519.

Evans, W. N. and Moore, T. J. (2011) 'The short-term mortality consequences of income receipt', Journal of Public Economics, 95(11-12): 1410-1424.

Forget, E. L. (2011) 'The Town with No Poverty', Canadian Public Policy, 37(3): 283-305.

Gibson, M., Hearty, W. and Craig, P. (2018) Universal basic income: A scoping review of evidence on impacts and study characteristics, Glasgow: What works Scotland.

Gibson, M., Hearty, W. and Craig, P. (2020) The public health effects of interventions similar to basic income: a scoping review. The Lancet Public Health, 5(3). DOI: $10.1016 / \mathrm{S} 2468-2667(20) 30005-0$.

Gilbert, R., Murphy, N. A., Stepka, A., Barrett, M., Worku, D. (2018) 'Would a Basic Income Guarantee Reduce the Motivation to Work?', Basic Income Studies, 13(2). DOI: 10.1515/bis-2018-0011

Gordon, N. J. (2014) 'The Conservative Case for a Guaranteed Basic Income', The Atlantic (Online), 6 August, https://www.theatlantic.com/politics/archive/2014/08/why-arentreformicons-pushing-a-guaranteed-basic-income/375600. [Accessed 10 January 2019].

Government Digital Service. (2020) 'Universal Credit', GOV.UK (Online), London: UK Government, <https://www.gov.uk/universal-credit> [Accessed 25 February 2020].

Haagh, L. and Rohregger, B. (2019) Universal basic income policies and their potential for addressing health inequities, Copenhagen: WHO.

Halliday, J. (2019) 'Hull asks to be first UK city to trial universal basic income', The Guardian (Online), 19 January, <https://www.theguardian.com/uk-news/2020/jan/19/hulluniversal-basic-income-trial> [Accessed 20 January 2020].

Hannan, M. T. (1978) 'Noneconomic Outcomes', In, J. Palmer and J. Pechman (eds.), Welfare in Rural Areas: The North Carolina-Iowa Income Maintenance Experiment, Washington DC, Brookings Institution, pp. 183-210.

Harrop, A. \& Tait, C. (2017) Universal basic income and the future of work, London: Fabian Society \& TUC.

Haushofer, J. and Shapiro, J. (2016) 'The Short-term Impact of Unconditional Cash Transfers to the Poor', The Quarterly Journal of Economics, 131: 1973-2042.

Haushofer, J. and Shapiro, J. (2018) The long-term impact of unconditional cash transfers, Working paper (Online), <https://bit.ly/2zTB4pg> [Accessed 10 January 2019].

Henley, J. (2018) 'Finland to end basic income trial after two years', The Guardian, 23 April, $<$ www.theguardian.com/world/2018/apr/23/finland-to-end-basic-incometrial-aftertwo-years>. [Accessed 27 January 2020]. 
Henley, J. and agencies (2019) 'Finland's “free cash" experiment fails to boost Employment', The Guardian, 8 February, <www.theguardian.com/world/2019/feb/08/finland-freecash-experiment-fails-to-boost-employment> [Accessed 27 Jan 2020].

Hirsch, D. (2019) A Minimum Income Standard for the United Kingdom in 2019, York: Joseph Rowntree Foundation, <https://www.jrf.org.uk/report/minimum-income-standard-uk2019> [Accessed 19 February 2020].

Howard, M. (2005) 'Basic Income, Liberal Neutrality, Socialism, and Work', Review of Social Economy, 63(4), 613-631.

John, E., Thomas, G. and Touchet, A. (2019) Disability Price Tag 2019, London: Scope, <https://www.scope.org.uk/campaigns/extra-costs/disability-price-tag> [Accessed 19 February 2020].

Johnson, E. A. and Spring, E. (2018) The Activity Trap, Manchester: Activity Alliance.

Johnson, E. A., Johnson, M. T. and Webber, L. (2020) 'Measuring the health impact of Universal Basic Income as an upstream intervention', Evidence \& Policy. DOI: $10.1332 / 174426420 X 15820274674068$.

Johnson, M. T. and Johnson, E. A. (2019) 'Stress, Domination and Basic Income', Social Theory \& Health, 17(2): 253-271.

Johnson, M. T., Geyer, R., Degerman, D. (2019) 'Exploring the health case for a trial of Universal Basic Income', Basic Income Studies, 14(2): 1-11. DOI:10.1515/bis-20190008.

Kangas, O., Jauhiainen, S., Simanainen, M. and Ylikännö, M. (2019) The basic income experiment 2017-2018 in Finland, Helsinki: Ministry of Social Affairs, $<$ https://julkaisut.valtioneuvosto.fi/handle/10024/161361> [Accessed 19 February 2020].

Kehrer, B.H. and Wolin, C.M. (1979) 'Impact of income-maintenance on low birth-weight', Journal of Human Resources, 14(4): 434-462.

Kershaw, D. and J. Fair (1976) New-Jersey Income-Maintenance Experiment Vol. 1. Operations, Surveys, and Administration, New York: Academic Press.

Labour Party (2019) The Labour Party Manifesto 2019, London: The Labour Party.

Living Wage Foundation (2020) 'The Calculation', Living Wage Foundation (Online), <https://www.livingwage.org.uk/calculation> [Accessed 19 February 2020].

Macintyre, S. (2012) 'Evidence in the development of health policy', Public Health, 126(3): 217-219.

McGuinness, F., Booth, L. and Francis-Devine, B. (2019) Poverty in the UK. London: House of Commons Library, <https://researchbriefings.parliament.uk/ResearchBriefing/Summary/SN07096> [Accessed 19 February 2020].

Mehra, S., Stopnitzky, Y. and Alloush, M. (2018) 'Economic Shocks and Personality Traits of the Ultra-Poor', Working Paper (Online). DOI: 10.13140/RG.2.2.29462.80960.

Mell, H., Baumard, N. \& André, J. B. (2019) 'Time is money', EcoEvoRxiv, https://doi.org/10.32942/osf.io/7d56s.Morris JN, Donkin AJM, Wonderling D, et al. (2000) 'A minimum income for healthy living', Journal of Epidemiology \& Community Health, 54: 885-889.

Mullainathan, S. and Shafir, E. (2014) Scarcity [Kindle], London: Penguin

Nettle, D. (2010) 'Why are there social gradients in preventative health behavior?', PLoS One, 5: e13371.

Nussbaum, M. (1999) Sex and Social Justice, New York: Oxford University Press.

Pepper, G. V. \& Nettle, D. (2017) 'The behavioural constellation of deprivation', Behavioural and Brain Sciences, 40: e314.

Pettit, P. (2007) 'A republican right to basic income?', Basic Income Studies, 2: 1-8. 
Pohjanpalo, P. (2019) 'Free money didn't help people find jobs, Finland says', Bloomberg.com, 8 February, <www.bloomberg.com/news/articles/2019-02-08/finland-findsbasicincome-failed-to-boost-employment $>$ [Accessed 27 January 2020].

Pybus, K. J., Pickett, K., Prady, S. L., Lloyd, C. \& Wilkinson, R. (2019) 'Discrediting experiences: Outcomes of eligibility assessments for claimants with psychiatric compared to non-psychiatric conditions transferring to Personal Independence Payments in England', British Journal of Psychiatry Open, 5(2): e19, https://doi.org/10.1192/bjo.2019.3.

Roberts, N. C. and King, P. J. (1991) 'Policy Entrepreneurs', Journal of Public Administration Research and Theory, 1(2): 147-175.

Ruckert, A., Huynh, C. and Labonté, R. (2018) 'Reducing health inequities', Journal of Public Health, 40: 3-7.

Salehi-Isfahani, D. and Mostafavi-Dehzooei, M. H. (2018) 'Cash transfers and labor supply', Journal of Developmental Economics, 135: 349-367.

Saltelli, A. and Giampietro, M. (2017) 'What is wrong with evidence based policy, and how can it be improved?', Futures, 91: 62-71.

Schneiderman, N., Ironson, G. and Siegel, S. D. (2005) 'Stress and health', Annual Review of Clinical Psychology, 1: 607-628.

Sen, A. (1980) 'Equality of What?', in, S. McMurran, ed., Tanner Lectures on Human Values, Cambridge: Cambridge University Press, pp. 137-162.

SEWA Bharat (2014) A little more, how much it is, New Delhi, SEWA Bharat and UNICEF.

Standing, G. (2019) Basic Income as Common Dividends, Progressive Economic Forum: London.

The Lancet (2020) 'Editorial: Income, health, and social welfare policies', The Lancet Public Health, 5, e127.

Valero, J. (2019) 'Finnish finance minister: "case closed" for Universal Basic Income', www.euractiv.com, 12 February, <www.euractiv.com/section/economy-jobs/ interview/finnish-finance-minister-case-closed-for-universal-basic-income/> [Accessed 27 Jan 2020].

van der Kolk, B. (2014) The Body Keeps the Score, New York: Allen Lane.

Van Parijs, P. (2004) 'Basic Income', Politics \& Society, 32: 7-39.

Widerquist, K. (2005) 'A failure to communicate: What (if anything) can we learn from the negative income tax experiments?', Journal of Socio-Economics, 34: 49-81.

Working Group on Inequalities in Health (1980) Black Report, London: Department of Social Services, <https://www.sochealth.co.uk/national-health-service/public-health-andwellbeing/poverty-and-inequality/the-black-report-1980/black-report-foreword/> [Accessed 2 August 2020]. 